\title{
ANALYSIS OF THE DEVELOPMENT PROCESS OF THE TERRITORIAL PRODUCTIVE AND TECHNOLOGICAL POTENTIAL OF THE REGION'S CONSTRUCTION ORGANIZATIONS
}

\author{
Vladimir Viktorovich Bredikhin ${ }^{1 *}$, Bredikhina Natalia Vladimirovna ${ }^{1}$, Aksenteva luliia Yurievna $^{2}$ \\ 'Southwest State University, Kursk, Russia \\ ${ }^{2}$ Corvinus University of Budapest, Hungary
}

One of the most important economic tasks of construction activities actors is the correct estimation of their initial state in terms of the possibilities for further development. The solution of these complex problems under the conditions of limited resources puts forward the problem of quantitative and qualitative measurement of available resources and productive and technological potential of organizations. The paper discusses a system analysis of the construction organization and the components of the productive and technological potential as subsystems that have a qualitative and quantitative measurement of the maximum possible efficiency of resources usage by a construction organization under conditions of the rational construction management and the interaction of business entities in the investment sector.

Key words: territorial investment and construction complex, construction organization, productive and technological potential, potential intensity of territorial production and construction system of the region

\section{INTRODUCTION}

One of the most important economic tasks of construction activities actors is the correct estimation of their initial state in terms of the possibilities for further development. The quantitative and qualitative characteristics of available resources and the ability to properly respond to a rapidly changing market situation determine their potential. The potential is the basis for all strategic decisions made in organizations and determines the goal of the organization's production policy, the program of action, and ways to implement this program.

The solution of these complex problems under the conditions of limited resources puts forward the problem of quantitative and qualitative measurement of available resources and productive and technological potential of organizations. The correctness of measurements and calculations influence on the decision-making strategy which provides benefits from the current reorientation of productive capacity, material, labor, and innovative resources to produce marketable construction products and services. This causes a change in policy, economic relations with potential investors, customers, suppliers of materials and equipment, and supply industries [1].

\section{CHARACTERISTICS OF THE TOTAL POTENTIAL OF THE ORGANIZATION}

There are several factors that form the organization's aggregate potential in the market economy conditions [2]:

- The state of market relations.

- Competitiveness.

- The pace of scientific and technological progress.

- Information base.
- Productive use of the aggregate labor force.

- Level of organization and production management.

- Efficiency of using productive assets.

- The efficient use of material and energy resources.

- The level of intellectual work of workers.

- Social and cultural development of society.

- Marketing research applications.

In our opinion, the impact of these factors on the organization's potential has the following feature: each factor does not affect the aggregate, but its certain internal constituent elements. Thus, the organization's potential is formed as an integrated result of the productive and technological capacities of all its internal components.

The aggregate potential of a construction organization is a combination of all its capacities that involves the maximum possible use of all available resources to produce high-demand and competitive construction products with an appropriate implementation of the latest equipment and technologies, rational operation, scientific labor organization and production, and environmental protection. The main determining component of construction products (services) output is the productive and technological potential [3].

\section{ANALYSIS OF PRODUCTION AND TECHNICAL POTENTIAL OF THE ORGANIZATION}

The productive and technological potential characterizes the productive and technological capabilities of all main elements of production as an entire system that can adapt to the conditions of a market economy. In other words, it is the interaction of labor, material, energy, and information technology resources in a given specific 
period. Potential components should be considered as subsystems or corresponding potentials due to the consistency of construction organizations.

Thus, according to the author's concept, the productive and technological potential is an integral quantitative estimation of the maximum possible efficiency of resources usage by a construction organization under conditions of the rational construction management and the interaction of business entities in the investment sector. The definition of productive and technological potential as an integral system with elements serving a common goal requires focusing on the structural aspect of the problem with the analysis of the development and interaction of the main elements (resources).

On the grounds the productive and technological potential is a quite complex and comprehensive concept, it is necessary to evaluate its components only as comparable standardized indicators. This will allow to calculate an integrated indicator of the productive and technological potential of the organization.

The current state of the market economy study allowed us to conclude that the successful development of investment and construction activities of the territorial governing bodies relies heavily on the choice of an effective development and management for expanding the market for the production of finished construction products output and sales in response to reconstruction of the existing buildings $[4,5]$.

\section{SETTING AND SOLVING OF THE MAIN TASKS}

Goals setting and solution of the main production and investment problems requires the growth opportunities for construction and installation works (CIW) of construction organizations and the potential intensity of construction industry enterprises. Generally, the potential intensity of any production system is an assessment of the enterprise's potential capabilities in terms of the output of the relevant type and quality (in kind or value terms) for a certain period (usually an annual planning period). In other words, the potential intensity is an integral assessment of productivity (capacity) for any construction company [6].

However, from the territorial investment and construction complex perspective, the potential intensity of the industrial construction system (a construction organization and a construction industry enterprise in the study of reference) characterizes the acceptable level of its investment resources and reconstruction opportunities of residential real estate.

The authors consider the region production potential as the real output that can be produced with full usage of available investment resources in a given region, existing manufacturability, availability of production factors and resources required. The technical potential is considered as the aggregate capability of the available technical and technological resources of the economic entity of the territorial investment and construction complex
(TICC) to carry out industrial and economic activities to produce finished construction output, to satisfy the needs of the population and social demand for these products, ensuring production and consumption development. The authors propose to consider the aggregate productive and technological potential as the final characteristic of the potential intensity of a construction enterprise that includes not only the internal indicators of the system capacity and the potential intensity but also productive-economic indicators that shows the current state of competitive construction products market. The most important step of the region productive and technological potential modelling is a description of its performance and development. This step involves the following activities:

1. goals setting of the regional potential performance;

2. criteria selection for the regional potential performance;

3. determination of the regional potential place in a high-order system, a description of the external environment, the form and mechanisms of interaction with it;

4. a description of the regional potential internal structure and the function of the individual elements;

5. the identification of the data connection between the external environment and regional potential, as well as between its subsystems and components;

6. the conceptualization of the regional potential development mechanism.

As already noted, it is very important in the description of the regional potential as a system is the definition of the objectives of its functioning.

For complex socio-economic systems, to which the region belongs, the multi-system of goals is also characteristic $[7,8]$.

These goals may include:

a) stabilization and sustainable development of the region;

b) ensuring employment of the active population and the absence of social tension in the region;

c) ensuring a stable financial condition of the regional economy;

d) reproduction of natural conditions that ensure the livelihoods of the population of the territory at an ecologically safe level;

e) ensuring the conditions for self-reproduction of the regional potential of the territory.

\section{APPROACHES TO THE SELECTION OF CRITERIA INDICATORS}

As previously stated, the goals setting of the regional potential performance is very important for its description as a system.

Multi-system of goals is also applicable to complex socio-economic systems (to which the region belongs) $[7,8]$. 
These goals may include:

a) stabilization and sustainable development of the region;

b) ensuring employment of the active population and the absence of social unrest in the region;

c) ensuring the financial solvency of the regional economy;

d) reproduction of environmental conditions that ensure the livelihoods of the population of the territory at an ecologically safe level;

e) ensuring the conditions for self-reproduction of the regional potential of the territory.

There are two approaches for the selection of criteria characterizing the value of the regional potential. The value of the productive and technological potential can be expressed by the parameters of its structural state and an integrate reliability rate. This approach is due to the assumption of proportionality between the functional capabilities of the whole system and its structural parameters. In practice, these opportunities depend on production conditions and general economic factors (including inter-industry relations).

The second approach is based on the performance indicators of the regional potential. The performance effectiveness of the regional potential can be determined by one integrated or several individual indicators each of which characterizes the achievement of a particular goal of the regional potential performance. However, in the latter case, the problem of multicriteria and the need for reduction of several criteria to one arises. Therefore, we propose the option of assessing the effectiveness of the region performance based on the selection of the main criterion. There are different experts' opinions about the selection $[9,10,11,12]$. Summarizing the conclusions of previous studies, we can propose the following indicators for the assessment of the regional system performance:

- gross regional product (GRP);

- $\quad$ net regional product (NRP);

- national income (NI);

- personal income (PI);

- revenues of local authorities (RLA).

Above mentioned indicators reflect the target interests of individual groups of territorial entities in a varying degree. The interests of state administration of the territory are linked with its economic potential through the revenues of local authorities (RLA): the higher the economic potential, the more possibilities of the territory for income generation. If the personal income of citizens $(\mathrm{PI})$ is the main criterion, the goal of the regional potential performance is realized through the increasing of consumption fund increasing and the human wellbeing. Many researchers $[13,14,15]$ believe that the national income (NI) measured in comparable prices should be the main criterion the region development. This indicator does not include a compensation fund of consumed means of production and re-accounting of material costs but characterizes the net result of public production which increases the amount of tangible and intangible goods at the society disposal.

At the same time, national income does not include depreciation deductions which can be a source of financing simple and expanded reproduction of capital stock which lowers the accumulation fund and the regional reproductive potential. Besides, the national income does not indicate the accumulation and consumption funds ratio which does not fix the contradiction between current consumption and future income from accumulation. Also, indirect taxes are not included in the national income which is a source of public expenditures financing and transfer payments despite subjective setting. The last drawback of national income as the main criterion can be eliminated by using the net regional product (NRP) indicator. However, this indicator does not include a compensation fund of consumed means of production (depreciation).

According to the analysis carried out by the authors, the most acceptable indicator of the effectiveness of the regional system performance and the main criterion in the regional potential model is the gross regional product (GRP). Gross regional product characterizes the value of goods and services produced in all sectors of the economy (including in the construction sector) intended for final consumption, accumulation and net export. The advantage of this indicator is the possibility of calculation the previously listed indicators.

There are two opinions about the selection of the main criterion of the regional system performance in the scientific literature. P. Oldak [16, 17] gives an example of using "net national welfare" indicator which is the algebraic sum of consumption of household goods (products and services, accumulated property), free time goods and characteristics of "negative welfare" (environmental pollution urbanization damage). The suggestion of switching to multi-criteria characteristics for the regional performance assessing is made in the same paperwork. These multi-criteria characteristics are derived from the system of social wealth accounts as:

- material wealth accumulation;

- services flow;

- knowledge accumulation;

- condition of reproducible natural resources;

- public health.

The multi-criteria approach to the regional system performance assessing is based on its relationship with other subsystems - social and natural. Each of the subsystems is characterized by its own set of indicators. The social subsystem is characterized by indicators of goods and services consumption, life expectancy, morbidity rate, etc. The natural subsystem is characterized by the state of reproducible and non-reproducible natural resources, levels of air, water and soil pollution, the level of degradation and the assimilation potential of the natural environment, etc. 
A summarizing criterion for regional system performance as a weighted sum of particular criteria can be suggested based on these indicators. Experts determine the weight of a particular criterion by the preference matrix. However, experts' involvement can be the reason of calculations subjectivity. The method of a particular criteria reduction to summarizing one by the means of valuation of criteria is preferable. In this case, the summarizing criterion valuation is determined by the cost of the accumulated goods or the damage suffered. The practical implementation of this approach has difficulties with the expression of social and natural characteristics of subsystems in monetary terms. Also, the regional productive and technological potential performance modeling involves a description of the organizational structure of the system, the allocation of connections and relationships between components, the characteristics of the external and internal environment, and factors and conditions for the regional potential performance. At the same time, informal and formal description of the system and the processes of its stable performance is distinguished. The informal description is initial as compared with the formal.

\section{CONCLUSION}

An informal description of the regional productive and technological potential starts with determining its place in a high-order system and the components of the external environment [18]. A high-order system at the regional level is a territory system (for example, an administrative area), which includes: production, economic, social, natural and information subsystems. Each of these systems has its potential. Thus, the regional potential as a subsystem is part of the potential of the corresponding territory.

The external environment for regional potential is represented by:

a) the territory population as the social system component;

b) the natural environment which is the human environment, a source of natural resources and the production of goods (services);

c) the system of state administration of the territory;

d) related socio-economic systems of territorial entities.

The internal structure of the regional potential includes the potentials of the upper level of description (labor, production, technical, natural-resource, innovative), which consist of lower-level potentials. All components of the regional potential should be considered in the context of the sectors of the national economy and administrative regions.

\section{REFERENCES}

1. Kulakov Yu.N., Silantyeva T.N., Bredikhina N.V. The main problems of the formation and implementation of urban planning policy // Bulletin of the South-West State University, Series: Engineering and Technology.- 2012.- No. 2. Part 3.- P.156-163.

2. Shtulberg B.M. Regulation of territorial development in a market economy. - M .: Nauka, 2003 .- 127 p.

3. Bredikhin V.V. Methodology of the formation and development of the aggregate production and technical potential of the city and the region territories. - Kursk: South-West State University, 2012.- 121 p.

4. Vidyapin V.I., Stepanov M.V. Regional economy. - M .; INFRA-M, 2007 .-- 666 p.

5. Glazyrin M.V. production and social complexes of the regions and their management. - M .; Novgorod, 1997 .- 94 p.

6. Grabovy P.G., Bredikhin V.V., Kapirin D.A. Problems of management of production and technical potential of territorial and investment construction complex in a competitive environment// Real Estate: Economics, management. - №1, 2012. - p.41-51.

7. Regional development: the experience of Russia and the European Union / [A.G. Granberg, I.M. Busygina, V.G. Vvedensky and others]; Head auth. collective and resp. ed. A.G. Granberg - M .: Economics, 2000 .-- 438 p.

8. Bredikhin V.V. Analysis of investment and construction projects in the formation and implementation of programs of territorial and spatial development of the city. Bulletin of the South-West State University. Series "Economics. Sociology. Management». №2, 2012. - P.70-76.

9. Gadzhiev Yu.A. Foreign theories of regional economic growth and development // Regional Economy. 2009. No. 2.- p. 45-62.

10. Shtulberg B.M., Vvedensky V.G. Regional policy of Russia: theoretical foundations, tasks and implementation methods.- M .: Helios ARV, 2000.- 206 p.

11. An Agenda for a Reformed Cohesion Policy. A Place-Based Approach to Meeting European Union Challenges and Expectations. Independent Report Prepared at the Request of Danuta Hubner, Commissioner for Regional Policy by Fabrizio Barca. April, 2009 .-- 29 p. 12.

12. Garretsen H., McCann P., Martin R., Tyler P. The Future of Regional Policy // Cambridge Journal of Regions, Economy and Society. - 2013.- No. 6.- Pp. 179-186.

13. Pike A., Rodriguez-Pose A., Tomaney J. Local and Regional Development. London: Routledge, 2006 .$328 \mathrm{p}$. 
14. Pestsov S.K. In search of a new paradigm of regional development: foreign experience and Russian reality // Regional Studies.-2018. T. 5. No. 5.- S. 93-109.

15. Roshchenko A.V. National product and the problems of its measurement. - M .; BSEU, 2008 .-- 587 p.

16. Oldak P.G. The Formation of Modern Economic Thinking.- Novnsibirsk: Nauka, 1989.- 158 p.
17. Oldak P.G. Preservation of the environment and the development of economic research. - Novosibirsk: Nauka, 1980 .-- 160 p.

18. Bredikhina N.V. Basic principles of production-and-technical potential capacity formation in the construction industry of region// Journal of Applied Engineering Science.- 15(2017)4, 477.- P. 495-497. 